\title{
OS DESAFIOS DA GESTÃO DE PARQUES URBANOS: ESTUDO DE CASO DO PARQUE MUNICIPAL DO DISTRITO INDUSTRIAL, UBERLÂNDIA, MG
}

\section{Alessiane Silva Justino ${ }^{1}$}

Diogo Costa Nascimento ${ }^{2}$

\begin{abstract}
RESUMO
A necessidade de se pensar o espaço urbano ligado a questões do meio ambiente é de grande importância, visto que com a expansão urbana e o crescimento demográfico as cidades carecem cada vez mais de áreas verdes de qualidade, neste cenário surgem os parques urbanos que proporcionam a população espaços de lazer, bem estar. Deste modo o artigo tem como objetivo realizar um diagnóstico da situação do Parque Municipal do Distrito Industrial, buscando a partir da situação encontrada propor um zoneamento para o parque, contribuindo para os diversos usos, bem como para a qualidade de vida da população que utiliza deste espaço e seu entorno. A metodologia adotada foi pautada na elaboração de mapa de uso do solo, através de técnicas de geoprocessamento, utilizando imagens do satélite RapidEye AG; instrumentação e aplicação de questionários, por meio amostragem aleatória simples para a população local, avaliação das condições situacionais do parque, analisando o uso e ocupação do solo face as diretrizes de conservação definidos e proposição de zoneamento ambiental. A partir da pesquisa realizada, foi possível concluir que uma boa qualidade na gestão de parques urbanos, se faz necessário para que se tenha um ambiente saudável para a manutenção da qualidade de vida. Assim foi constatado que no Parque Municipal do Distrito Industrial é necessário sérias intervenções e uma boa gestão, no que se refere a preservação da natureza, segurança, infraestrutura e lazer para que a população se sinta parte integrante deste parque, de modo a contribuir para sua melhoria e preservação.
\end{abstract}

PALAVRAS-CHAVE: Parques Urbanos. Zoneamento. Gestão.

\section{THE CHALLENGES OF URBAN PARKS MANAGEMENT: PARK CASE STUDY HALL OF INDUSTRIAL DISTRICT, UBERLÂNDIA, MG}

\begin{abstract}
The need to think about urban space linked to environmental issues is of great importance, as with urban expansion and population growth cities need more and more green areas of quality, this scenario arise urban parks that provide the population leisure facilities, wellness. Thus the article aims

\footnotetext{
${ }^{1}$ Geógrafa, Mestranda em Arquitetura e Urbanismo, Faculdade de Arquitetura e Urbanismo, Universidade Federal de Uberlândia. alesseiane.geoufu@yahoo.com.br; Universidade Federal de Uberlândia. diogo_mg1990@yahoo.com.br
}

${ }^{2}$ Geógrafo, Mestrando em Meio Ambiente e Qualidade Ambiental, Instituto de Ciências Agrárias,
\end{abstract}




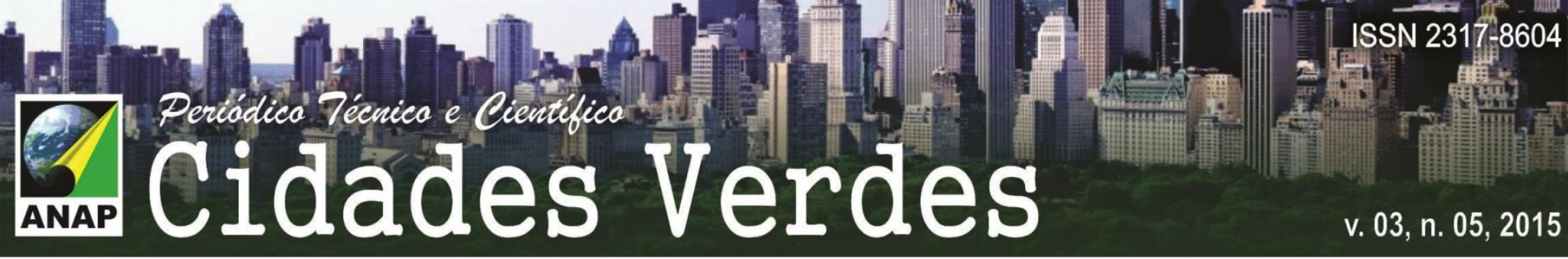

to conduct a diagnosis of the situation of the Municipal Park Industrial District, seeking from the situation found propose a zoning of the park, contributing to the various uses, as well as to the quality of life of the population using this space and its surroundings. The methodology adopted was based on the development map of land use through geoprocessing techniques using satellite imagery RapidEye AG; instrumentation and questionnaires, through simple random sampling for the local population, assessment of situational conditions of the park, analyzing the use and occupation against the defined conservation guidelines; environmental zoning proposal. From the survey, it was concluded that a good quality in the management of urban parks, it is necessary in order to have a healthy environment to maintain quality of life. Thus it was found that the Municipal Park Industrial District is required serious intervention and proper management, with regard to nature conservation, security, infrastructure and leisure for the population and so feel part of this park, in order to contribute to its improvement and preservation.

KEYWORDS: Urban Parks. Zoning. Management.

\section{LOS RETOS DE LA GESTIÓN DE PARQUES URBANOS: PARQUE DE CASO ESTUDIO PASILLO DE DISTRITO INDUSTRIAL, UBERLÂNDIA, MG}

\section{RESUMEN}

La necesidad de pensar en el espacio urbano relacionado con las cuestiones ambientales es de gran importancia, al igual que con la expansión urbana y las ciudades de crecimiento poblacional necesitar más y más zonas verdes de calidad, este escenario surgen parques urbanos que proporcionan la instalaciones de ocio de la población, el bienestar. Así, el artículo tiene como objetivo llevar a cabo un diagnóstico de la situación del Distrito Industrial Parque Municipal, en busca de la situación encontraron proponer una zonificación del parque, lo que contribuye a los diversos usos, así como a la calidad de vida de la población que utiliza este espacio y su entorno. La metodología adoptada se basó en el mapa de desarrollo de uso de la tierra a través de técnicas de geoprocesamiento utilizando imágenes de satélite RapidEye AG; instrumentación y cuestionarios, a través de un muestreo aleatorio simple para la población local, la evaluación de las condiciones situacionales del parque, analizar el uso y la ocupación contra las directrices de conservación definidas; propuesta de zonificación ambiental. A partir de la encuesta, se concluyó que una buena calidad en la gestión de parques urbanos, es necesario con el fin de tener un medio ambiente saludable para mantener la calidad de vida. Así se encontró que el Distrito de Parques Industriales Municipal se requiere la intervención seria y adecuada gestión, en lo que respecta a la conservación de la naturaleza, seguridad, infraestructura y de ocio para la población y así sentirse parte de este parque, con el fin de contribuir a su mejora y conservación.

PALABRAS CLAVE: Parques Urbanos. Zonificación. Gestión.

\section{INTRODUÇÃO}

Se faz necessário pensar na integração de questões ligadas ao espaço urbano e ao meio ambiente, visto o fenômeno do crescimento demográfico e a expansão urbana. Há algumas décadas as questões ligadas ao meio ambiente ainda 
não faziam parte de uma ampla discussão relacionando o urbano e a qualidade de vida, o meio ambiente era visto apenas como um possível meio de lazer aliado a sua estética.

De acordo com Ferreira (2005), a partir da década de 1980 quando a questão ambiental foi institucionalizada no aparelho estatal brasileiro, surgiu, então a necessidade de tratar o espaço urbano como um espaço em constante evolução, vinculado aos problemas ambientais e a qualidade de vida dos habitantes.

Neste cenário ambiental-urbano, a necessidade de um plano de manejo e uma gestão adequada para uma Unidade de Conservação, de acordo com o ICMBio, devem estar embasados não só no conhecimento dos elementos que conformam o espaço em questão, mas também numa interpretação da interação destes elementos.

Assim se faz necessário, conhecer os ecossistemas, os processos naturais e as interferências antrópicas que influenciam as unidades de conservação, de modo a considerar os usos que o homem faz de determinado espaço.

Segundo o ICMBio, o manejo de uma Unidade de Conservação implica em elaborar e compreender o conjunto de ações necessárias para a gestão e uso sustentável dos recursos naturais em qualquer atividade no interior e em áreas do entorno dela de modo a conciliar, de maneira adequada e em espaços apropriados, os diferentes tipos de usos com a conservação da biodiversidade.

Foi criada a Lei № 9.985/2000 que estabelece o Sistema Nacional de Unidades de Conservação (SNUC) que define o plano de manejo como um documento técnico mediante o qual, com fundamento nos objetivos gerais de uma Unidade de Conservação, estabelece o seu zoneamento e as normas que devem presidir o uso da área e o manejo dos recursos naturais. De acordo com o ICMBio, o plano de manejo estabelece a diferenciação e intensidade de uso mediante zoneamento, visando a proteção de seus recursos naturais e culturais; estabelece normas específicas regulamentando a ocupação e o uso dos recursos da Unidade de Conservação, zona de amortecimento e dos corredores ecológicos; reconhece a valorização e o respeito à diversidade socioambiental e cultural das populações tradicionais e seus sistemas de organização e de representação social. 
Apesar do SNUC não contemplar em seus grupos especificadamente a categoria de parques urbanos, este instrumento não impede aos Estados e Municípios a criação de UC's, mediante arcabouço jurídico próprio e competências constitucionais.

Neste sentido, os parques urbanos possuem uma função ecológica, estética e de lazer, com uma extensão maior do que as praças e jardins públicos. Com isso os parques urbanos, ganham relevância no cenário multidisciplinar das ciências ligadas ao urbanismo e ao meio ambiente, no tocante às áreas verdes, pois:

\begin{abstract}
As áreas verdes urbanas são consideradas como o conjunto de áreas intraurbanas que apresentam cobertura vegetal, arbórea (nativa e introduzida), arbustiva ou rasteira (gramíneas) e que contribuem de modo significativo para a qualidade de vida e o equilíbrio ambiental nas cidades. Essas áreas verdes estão presentes numa enorme variedade de situações: em áreas públicas; em áreas de preservação permanente (APP); nos canteiros centrais; nas praças, parques, florestas e unidades de conservação (UC) urbanas; nos jardins institucionais; e nos terrenos públicos não edificados. Exemplos de áreas verdes urbanas: praças; parques urbanos; parques fluviais; parque balneário e esportivo; jardim botânico; jardim zoológico; alguns tipos de cemitérios; faixas de ligação entre áreas verdes. (Ministério do Meio Ambiente. Disponível em : http://www.mma.gov.br/cidades-sustentaveis).
\end{abstract}

É válido ressaltar que são inúmeros benefícios que as áreas verdes possuem, inclusive os parques urbanos, que proporcionam a qualidade de vida da população, através da melhoria das condições atmosféricas, equilíbrio entre solo, clima e vegetação, diminuição dos níveis de ruído, além de proporcionar áreas de lazer e um embelezamento estético no espaço urbano.

Bovo e Conrado (2012), ressaltam que além da manutenção de áreas urbanas públicas e dos benefícios que elas proporcionam à cidade, cabe-nos refletir acerca das transformações destes espaços ao longo da história, consonante a dinâmica das relações sociais e sua influência sobre o espaço geográfico urbano como um todo, assim o parque urbano tem sido moldado ao longo do tempo pela ação do homem, criando e recriando espaços com múltiplas funções e usos.

Para Meunier, atualmente, parece consensual a compreensão dos parques urbanos como elementos importantes para o equilíbrio ambiental e o convívio social em uma grande cidade. Silva et al. (2007) enfatizam a destinação desses espaços urbanos ao lazer contemplativo e à prática de esportes, aliada ao fornecimento de 
serviços ambientais como conforto térmico, conservação e conhecimento da biodiversidade, controle da poluição sonora e do ar, considerados proporcionais à densidade de árvores existentes nos locais. Apesar de diferentemente conceituados por diversos autores, obedecendo diversas concepções, com enfoques ora mais paisagísticos, ora mais ambientalistas, ora mais arquitetônicos, os parques urbanos, como um elemento dinâmico da cidade, são, na verdade, o que a cidade percebe, ou seja, independente de definições, conceitos e classificações, os cidadãos e mais especificamente, os usuários dos parques, delineiam um perfil do que compreendem como parque urbano e, mais do que isso, do que necessitam como tal.

Com o objetivo de analisar a questão dos parques urbanos em escala local, este trabalho possui como área de estudo o Parque Municipal do Distrito Industrial, localizado no município de Uberlândia, situado entre as coordenadas $18^{\circ} 35^{\prime} 33^{\prime \prime} / 19^{\circ} 24^{\prime} 56^{\prime \prime}$ e e $47^{\circ} 53^{\prime} 41^{\prime \prime} / 48^{\circ} 29^{\prime} 21^{\prime \prime} \mathrm{W}$, no interior do estado de Minas Gerais, na mesorregião do Triângulo Mineiro/Alto Paranaíba (Figura 1). Este ocupa uma área total de aproximadamente $280.000 \mathrm{~m}^{2}$, e esta situado no setor norte da área urbana de Uberlândia, o parque se encontra entre os bairros Jardim Brasília, Pacaembu, Maravilha, Residencial Gramado e Setor Industrial. O Terminal Industrial pertencente ao Sistema Integrado de Transportes de Uberlândia (SIT), pode ser considerado como ponto de referência de conhecimento público para seu acesso, além disso, a área do parque pode ser facilmente localizado pela Rua Audina Carrijo, no início de sua área territorial ou/e em seu término pela Avenida Cel. José Teófilo Carneiro. 


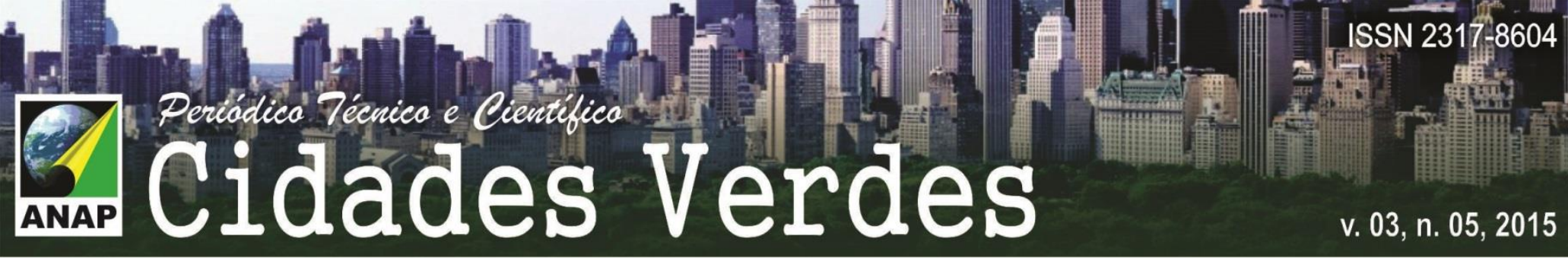

Figura 1: Localização do Parque Urbano do Distrito Industrial.

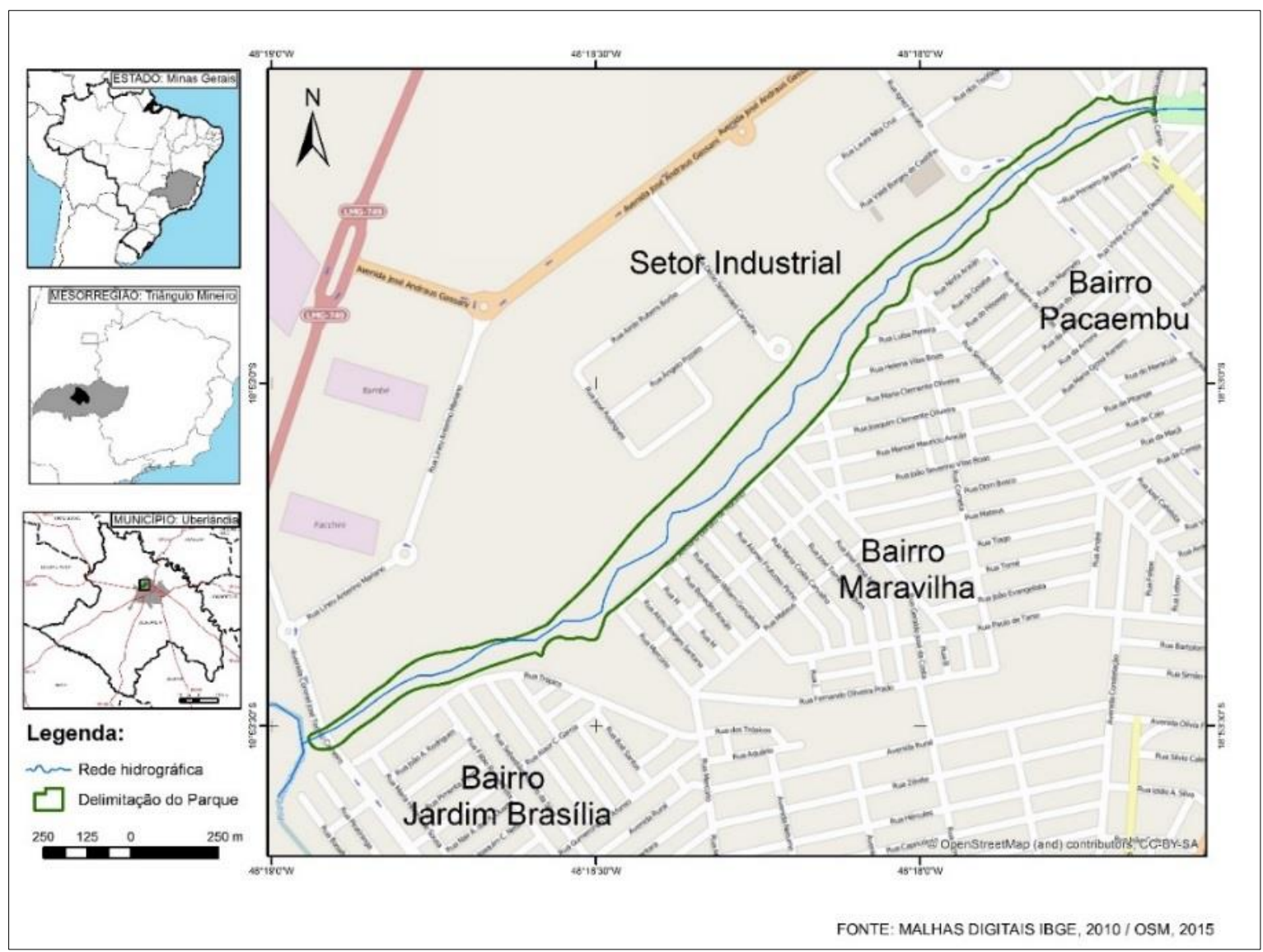

Organização: JUSTINO, A. S.; NASCIMENTO, D. C.,2015

O Parque Municipal Distrito Industrial também pode ser conhecido como Cinturão Verde, pois surgiu de uma parceria entre a Prefeitura de Uberlândia e a Souza Cruz (companhia de tabacos) que objetivava melhorar as condições ambientais dos bairros circunvizinhos, pois na época em que o mesmo foi concebido, as condições técnicas não preconizavam de forma eficiente, com o emprego de medidas compensatórias ou mitigadoras, de modo a contornar ou compensar a lógica vigente de produção industrial com ônus e efeitos ambientais adversos à saúde humana e qualidade do meio ambiente urbano.

O parque municipal do Distrito Industrial foi criado através do decreto municipal de ํㅜ 5.595 de 17 de setembro de 1992, instituído com Reserva Ecológica Municipal constituída de áreas verdes. Somente no ano de 1997 que o Parque foi

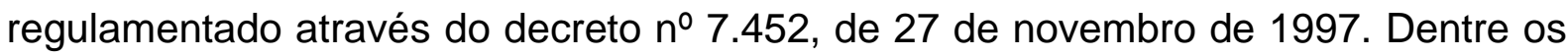


objetivos para sua criação destaca-se a necessidade de enriquecimento florestal da área, visando criar uma contenção viva entre o Distrito Industrial e os bairros vizinhos, amenizando assim os distúrbios devido a inevitável emissão de odores e partículas suspensas, provenientes das indústrias do Setor Industrial.

Anteriormente a área do atual do parque era utilizada, de forma irregular, para criação extensiva de animais, especialmente bovinos e equinos, e para fins de agricultura doméstica. Desde a sua concepção, a área de extensão territorial do mesmo é de domínio público municipal.

\section{OBJETIVO}

O presente artigo tem como objetivo principal realizar um diagnóstico da atual situação do Parque Municipal do Distrito Industrial, buscando a partir da situação encontrada propor um zoneamento para o parque, de modo a contribuir para os diversos usos, bem como para a qualidade de vida da população que vive e utiliza deste espaço e seu entorno.

\section{METODOLOGIA}

Como já discorrido, os parques urbanos desempenham papel fundamental no equilíbrio geoambiental de ambientes urbanos, corroborando para a harmonia paisagística, conforto térmico e bem estar das populações locais.

É sabido que em virtude das limitadas diretrizes orçamentárias dos municípios, a gestão de parques urbanos nem sempre é tida como prioridade, o que desemboca em ambientes degradados e suscetíveis a perca ou minimização das funções ecológicas, ambientais e sociais de parques e unidades de conservação urbanos.

Mecanismos como o ICMS ecológico, que funcionam como uma retribuição à execução de atividades ambientalmente positivas em seus respectivos espaços territoriais, podem ser uma importante forma de recursos para fomento de atividades 


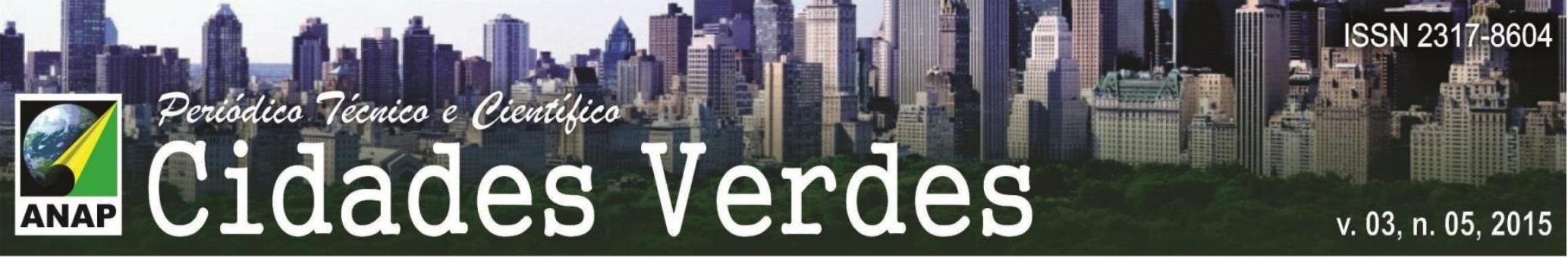

Figura 3: Gráficos sínteses de questionários aplicados.
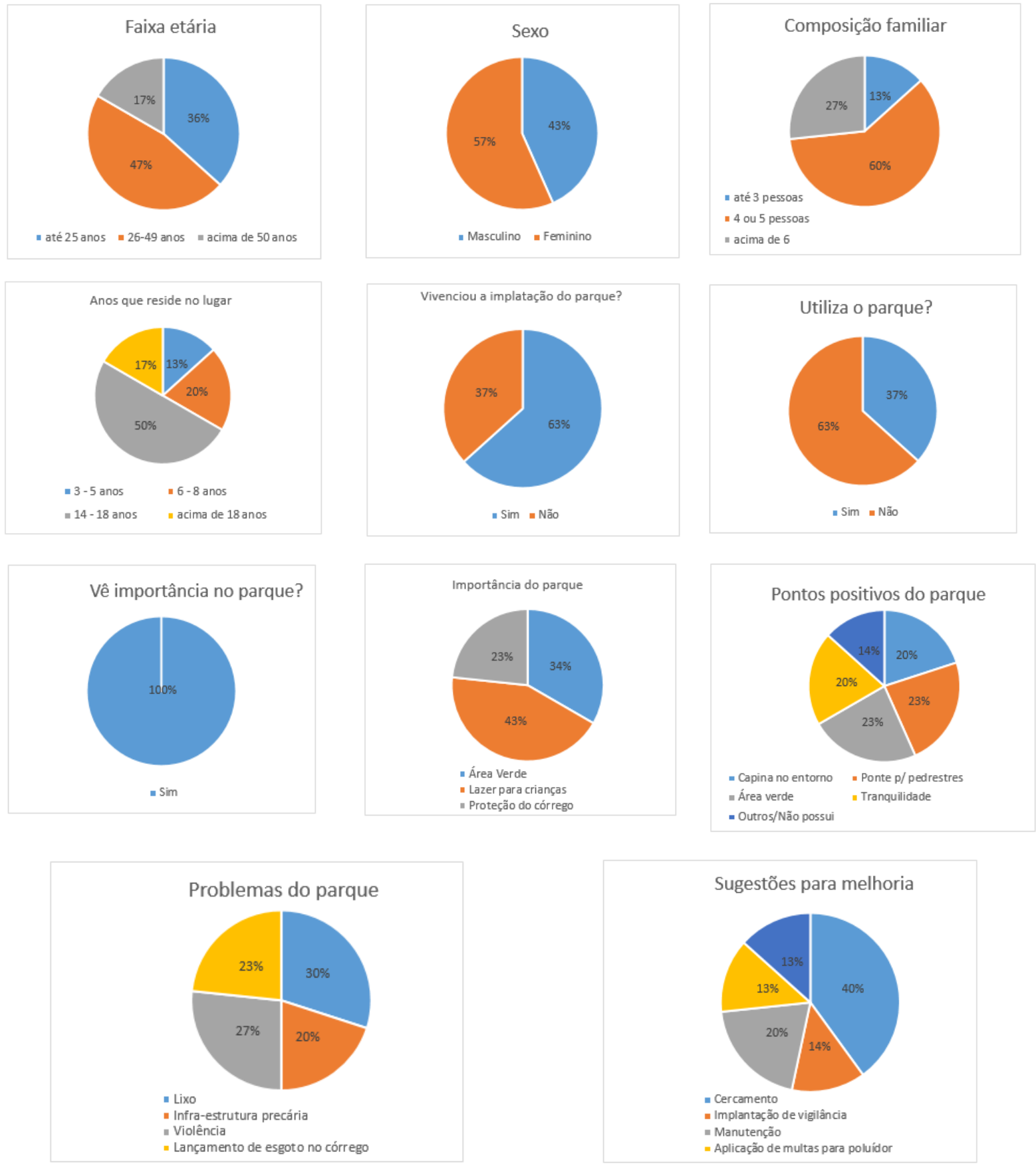

Organização: JUSTINO, A. S.; NASCIMENTO, D. C., 2015.

Ao observar as principais respostas da população quando questionada suas relações com o Parque Municipal do Distrito Industrial, percebe-se que a população possui grande apreço pela área verde, devido ao fato de terem vivenciado a 
implantação do parque, como mostra o gráfico da figura 3 , todavia $63 \%$ da população não utiliza das dependências deste, devido aos problemas levantados por eles, como lixo, infraestrutura precária, falta de segurança e lançamento de esgoto no córrego, ou seja, não existe uma adequada gestão por parte dos agentes públicos relacionados a qualidade do parque. Os moradores também ressaltaram os pontos positivos que o parque proporciona como a própria área verde ao entorno de suas casas que possibilita ambientes mais frescos e agradáveis, tranquilidade, uma ponte para pedestres que liga dois bairros, assim o tempo no deslocamento torn-se menor.

Como último questionamento realizado à população, foram relatados sugestões de melhoria pelos moradores pautadas no fechamento das entradas laterais, pois deste modo evita-se que a população entre no parque apenas para jogar lixo ou depredá-lo. Que a segurança no local seja efetiva para que a população tenha maior tranquilidade em relação algumas pessoas que são usuários de substâncias ilícitas no local. A limpeza também foi um ponto muito importante neste caso, pois fica evidente que a maior reclamação dos moradores principalmente os que fazem divisa com parque, é a grande quantidade de lixo e entulho, tendo como sugestão de melhoria a aplicação de multas para aqueles que fossem flagrados no ato de jogar lixo no local. As calçadas também foram pontos de melhoria ao entorno do parque, pois muitas pessoas utilizam o local para fazer caminhadas e no decorrer do percurso se deparam com locais que praticamente não possuem calçamento.

Sendo assim, um planejamento efetivo, levando em conta os anseios e perspectivas da população, deve ser considerado na gestão de parques urbanos e quando coerentes, incorporados no plano de manejo.

O plano de manejo se configura como instrumento essencial na gestão de unidades de conservação, independentemente de sua esfera ou categoria. No caso de unidades de conservação urbanas, este deve contemplar todas as possibilidades e restrições de uso, em função da dinamicidade de ambientes urbanos.

O zoneamento de unidades de conservação, considerando as zonas de diferentes graus de proteção e regras de uso, se constituí em uma das ferramentais mais importantes do plano de manejo (MMA, 2015). O zoneamento tem por objetivo 


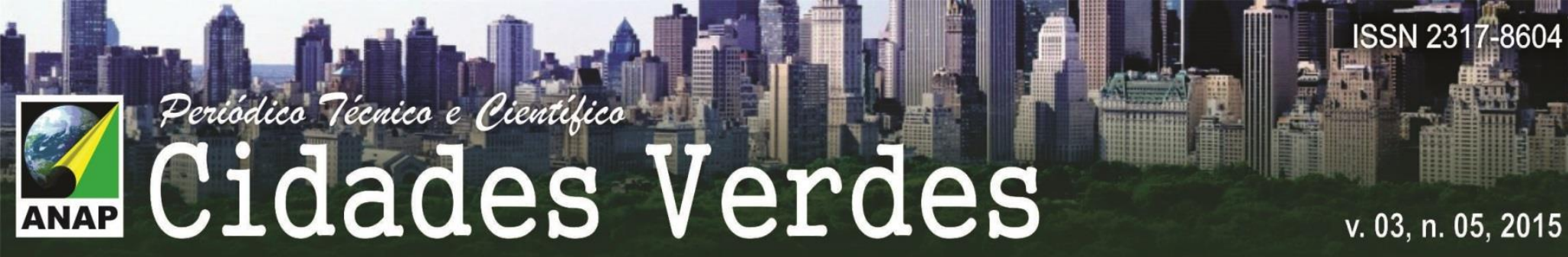

enquadrar áreas com objetivos, potencialidades e restrições semelhantes em função de fins educacionais, científicos e recreativos específicos. Todavia é um instrumento dinâmico que se interage com a realidade da UC.

Para critérios de zoneamento o Roteiro Metodológico de Planejamento do IBAMA para Parques, Reservas Biológicas e Estações Ecológicas (2002) propõe zonas em função de objetivos estabelecidos, conforme mostra o quadro a seguir:

Quadro 1: Propostas de zonas a serem consideradas em zoneamento de UCs

\begin{tabular}{|lllll|}
\hline I - Zona Intangível; & V- Zona Histórico-cultural; & IX - Zona de & Ocupação \\
II - Zona Primitiva; & VI - Zona de Recuperação; & Temporária; & \\
III - Zona de Uso Extensivo; & VII - Zona de Uso Especial; & X - Zona de Superposição \\
IV- Zona de Uso Intensivo; & VIII - Zona de Uso Conflitante; & Indígena; & \\
& & XI - Zona de Interf. Experimental; \\
& & XII - Zona de Amortecimento. \\
\hline
\end{tabular}

Fonte: Roteiro Metodológico de Planejamento do IBAMA para Parques, Ecológicas (2002)

Como objetivo deste trabalho procedeu-se o zoneamento considerado o Roteiro Metodológico de Planejamento do IBAMA para Parques, Reservas Biológicas e Estações Ecológicas, (2002), bem como os dados primários e secundários de caracterização da área, e as observações de campo, respaldadas nos objetivos de criação do Parque Municipal do Distrito Industrial, estabelecidas no decreto anteriormente citado.

Assim, observadas as características socioambientais e os objetivos de manejo definidos, foram propostas cinco zonas diferenciadas para o Parque Municipal do Distrito Industrial, conforme exposto a seguir:

- Zona de Uso Especial

Áreas necessárias à administração e atividades gerais de manutenção, fiscalização e apoio do Parque, abrangendo as infraestruturas correlatas. Compreenderá todas as áreas com infraestrutura e facilidades para a gestão do parque.

O objetivo geral da zona é garantir a instalação da infraestrutura necessária ao funcionamento do Parque, minimizando os impactos das mesmas e os efeitos das 


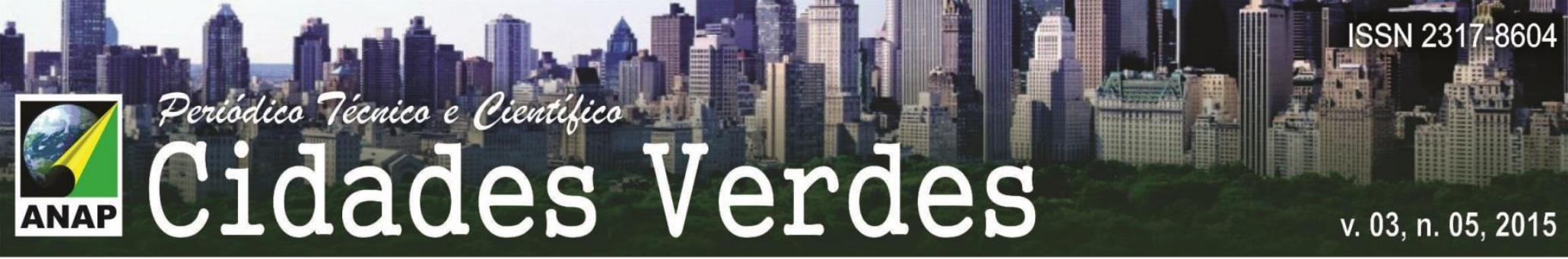

interferências humanas no ambiente natural, fornecendo suporte às suas atividades operacionais.

- Zona de Uso Intangível

Zona dedicada à proteção integral dos ecossistemas, dos recursos genéticos e ao monitoramento ambiental. Ocorre ao longo do córrego Liso, numa faixa marginal de 15 metros. O acesso humano somente será permitido em casos especiais e sob a permissão do órgão gestor.

Figuras 04 e 05: Exemplos de Áreas Intangíveis
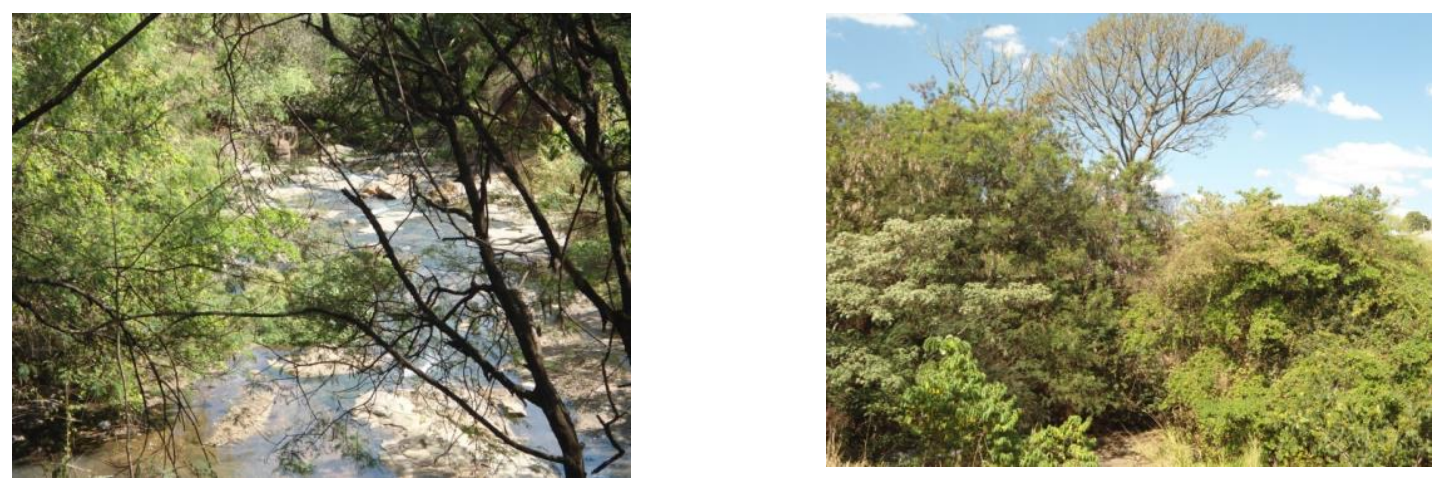

Fonte: JUSTINO, A. S.; NASCIMENTO, D. C., 2014.

- Zona de Ocupação Temporária

São áreas dentro do Parque onde ocorrem concentrações atividades de populações humanas residentes e as respectivas áreas de uso. É uma zona provisória, que uma vez relocada a população, deverá ser enquadrada como Zona de Recuperação e posteriormente incorporada à uma as zonas permanentes. 


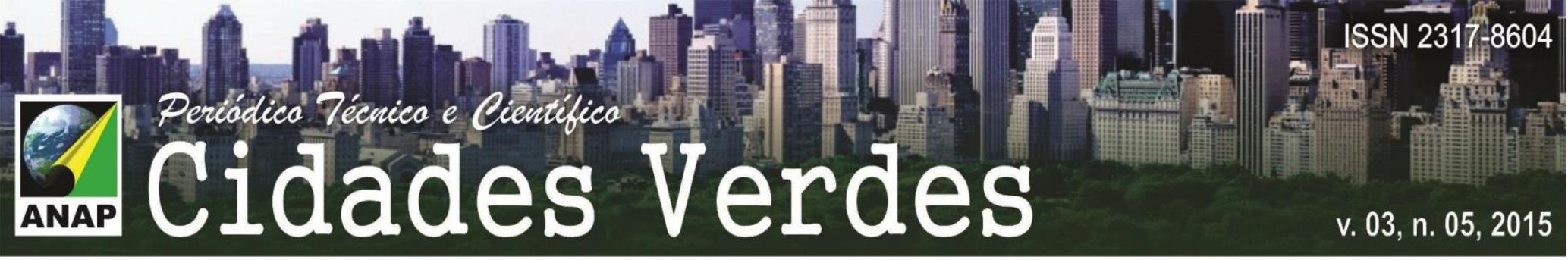

- Zona de Uso Conflitante

Constituem-se em espaços localizados dentro da Unidade, cujos usos e finalidades estabelecidos antes da criação do Parque, conflitam com os objetivos de conservação da área protegida. São áreas ocupadas por empreendimentos de utilidade pública, como, linhas de transmissão e estradas. Tem como objetivo de manejo contemporizar a situação existente, estabelecendo procedimentos que minimizem os impactos sobre a unidade de conservação.

Figuras 10 e 11: Exemplos de Zonas de Conflito
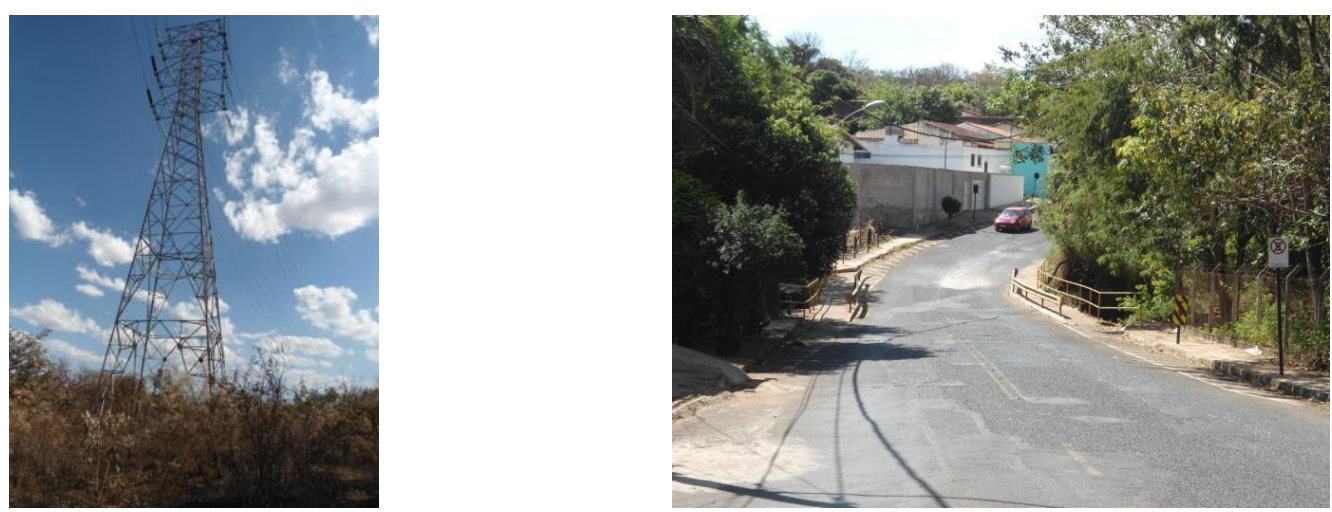

Fonte: JUSTINO, A. S.; NASCIMENTO, D. C., 2014.

Como produto do zoneamento proposto para o Parque Municipal do Distrito Industrial, foi elaborado um produto cartográfico indicando a localização espacial das zonas definidas (Figura 12). 


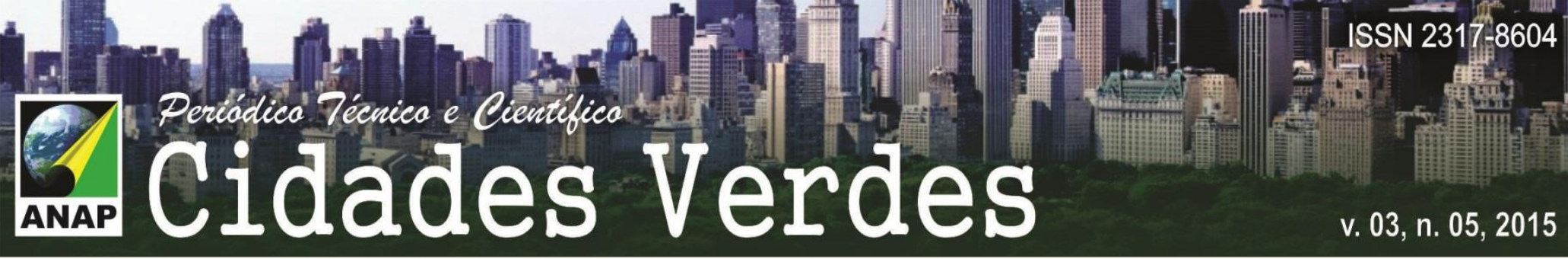

Figuras 12: Mapa de proposta de zoneamento para o Parque Municipal do Distrito Industrial.

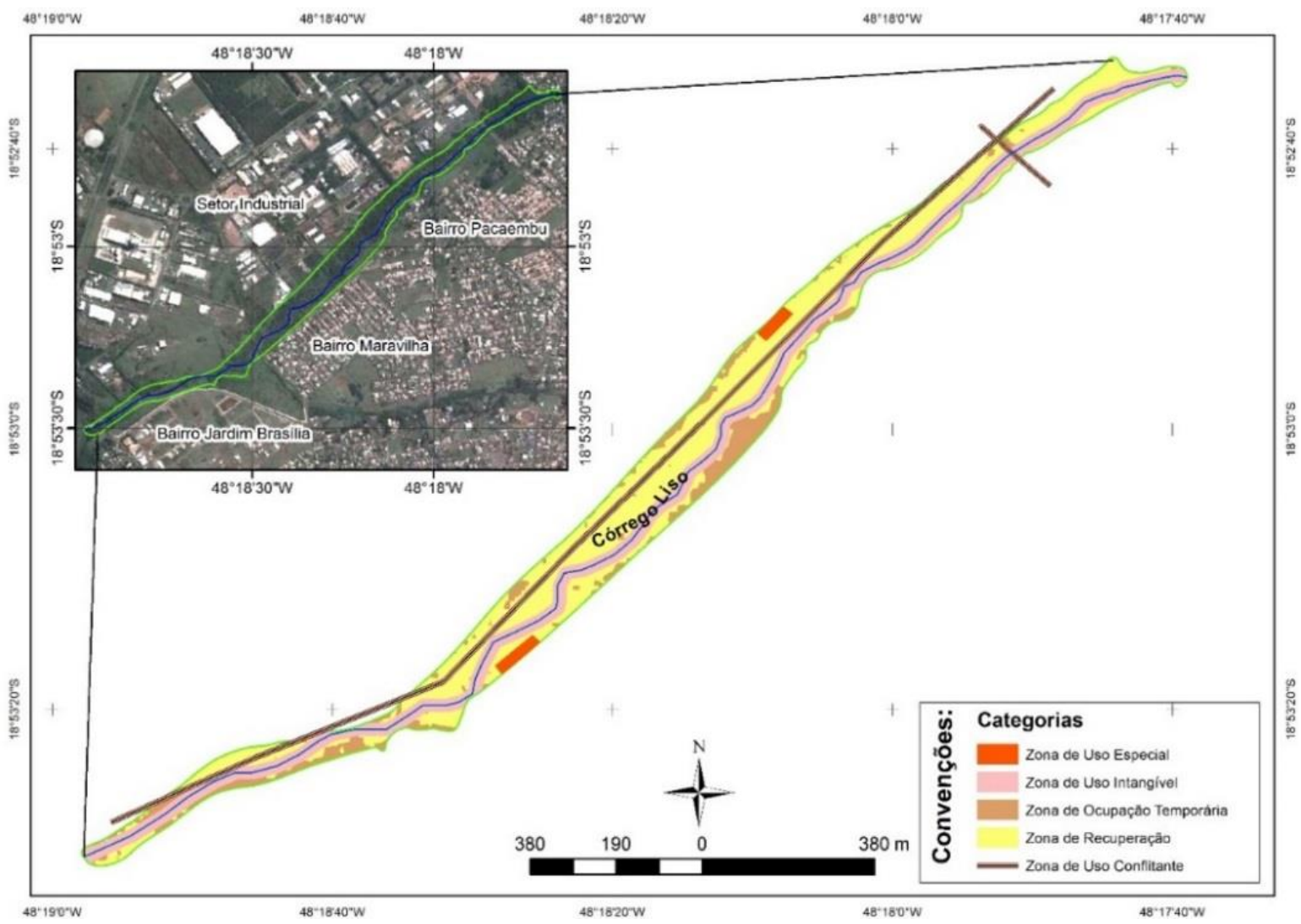

Organização: JUSTINO, A. S.; NASCIMENTO, D. C., 2015.

\section{CONCLUSÃO}

Os parques urbanos se constituem em áreas preponderantes para a qualidade ambiental urbana, em um aspecto amplo, uma vez que as cidades vem passando por um processo de urbanização cada vez mais acelerado, e nem sempre acompanhado do devido planejamento, considerando as dimensões ambientais, econômicas e sociais do desenvolvimento sustentável, essencial para o bem estar da humanidade.

A gestão de unidades de conservação em áreas urbanas deve ser embasado em rigorosos estudos que deverão ser incorporados no plano de manejo, levando em consideração os fins, fragilidades e potencialidade dessas áreas. O zoneamento, tido como uma ferramenta do plano de manejo, é fundamental para atingir os 
objetivos de conservação pretendidos, a partir de um planejamento dinâmico, considerando: planos, execução, monitoramento, avaliação e ajustes.

A partir da pesquisa realizada, foi possível concluir que uma boa qualidade na gestão de parques urbanos, se faz necessário para que se tenha um ambiente saudável para a manutenção da qualidade de vida. Assim foi constatado que no Parque Municipal do Distrito Industrial são necessário sérias intervenções e uma boa gestão, no que se refere a conservação dos recursos naturais além de segurança, infraestrutura e lazer para a população, para que esta se sinta parte integrante deste parque, de modo a contribuir para sua constante melhoria e conservação.

\section{REFÊRENCIAS}

BOVO, M. C. CONRADO, D. O parque urbano no contexto da organização do espaço na cidade de Campo Mourão (PR), Brasil. Caderno Prudentino de Geografia, Presidente Prudente, n.34, v.1, p.5071, jan./jul.2012.

BRASIL, Lei no 9.985, de 18 de julho de 2000. Regulamenta o art. 225, § 1‥ Incisos I, II, II e VII da Constituição Federal, institui o Sistema Nacional de Unidades de Conservação da Natureza e dá outras providências. Diário Oficial da República Federativa do Brasil, Brasília, DF, 9 set. 2000. Disponível em: . Acesso em: 24 de julho de 2014.

FERREIRA, A. D. Efeitos positivos gerados pelos parques urbanos: o caso do passeio público no Rio de Janeiro. Dissertação de Mestrado (Ciência Ambiental). 111f. Universidade Federal Fluminense. Rio de Janeiro. 2005.

Instituto Chico Mendes. Disponível em: http://www.icmbio.gov.br/portal/. Acessado em 23 de maio de 2015.

Ministério do Meio Ambiente. Disponível em: http://www.mma.gov.br/cidades-sustentaveis/areasverdes-urbanas/parques. Acessado em 23 de maio de 2015.

MEUNIER, I. M. J. PERCEPÇÕES E EXPECTATIVAS DE MORADORES DO GRANDE RECIFE-PE EM RELAÇÃO AOS PARQUES URBANOS. REVSBAU, Piracicaba - SP, v.4, n.2, p.35-43, 2009

RIBEIRO, J.F; WALTER,B.M.T. As principais fitofisionomias do bioma Cerrado. In: SANO,S.M; ALMEIDA,S.P; RIBEIRO, J.F. Cerrado: ecologia e flora. Brasília -DF: Embrapa Informação Tecnológica, 2008. P. 153-212.

PORTAL DA PREFEITURA DE UBERLÂNDIA. Parque Industrial do Distrito Industrial. Disponível em:

<http://www.uberlandia.mg.gov.br/secretaria.php?id_cg=144\&id=24> Acesso em: Acesso em: 24 de julho de 2014. 